\title{
UNIVERSITYOF
}

FORWARD

THINKING

WESTMINSTER用

WestminsterResearch

http://www.westminster.ac.uk/westminsterresearch

\section{Air transport liberalisation and airport dependency: developing a composite index}

Koo, T., Halpern, N., Papatheodorou, A., Graham, A. and Arvanitis, $\mathbf{P}$.

NOTICE: this is the authors' version of a work that was accepted for publication in the Journal of Transport Geography. Changes resulting from the publishing process, such as peer review, editing, corrections, structural formatting, and other quality control mechanisms may not be reflected in this document. Changes may have been made to this work since it was submitted for publication. A definitive version was subsequently published in Journal of Transport Geography, vol. 50, pp. 83-93.

Journal of Transport Geography is available online at:

https://dx.doi.org/10.1016/j.jtrangeo.2015.04.006

(C) 2016. This manuscript version is made available under the CC-BY-NC-ND 4.0 license http://creativecommons.org/licenses/by-nc-nd/4.0/

The WestminsterResearch online digital archive at the University of Westminster aims to make the research output of the University available to a wider audience. Copyright and Moral Rights remain with the authors and/or copyright owners.

Whilst further distribution of specific materials from within this archive is forbidden, you may freely distribute the URL of WestminsterResearch: ((http://westminsterresearch.wmin.ac.uk/).

In case of abuse or copyright appearing without permission e-mail repository@westminster.ac.uk 


\title{
Air transport liberalisation and airport dependency: developing a composite index
}

\begin{abstract}
Air transport liberalisation in Europe has produced some major changes to the networks operated by airlines and the services available at airports. Within this context the degree of airport dependency in terms of market, spatial and temporal concentration is important to know from an economic geography and risk management perspective. A composite index called the Airport Dependency Index (ADI) is developed to measure airport dependency based on the concept of the relative Gini coefficient. Liberalisation has had varying impacts depending on the size and type of airport and so a comparison is made of the degree of dependency at a large sample of European airports using the ADI. The ADI has the potential to provide insight on the sustainability and worthiness of financing airport projects, and on whether airports should diversify further their activities by investing in the growth and expansion of their network.
\end{abstract}

Keywords: Air transport liberalisation; Airport Dependency Index (ADI); Gini coefficient; European airports.

\section{Highlights}

- A composite Gini-based index is developed to measure airport dependency.

- Dependency is measured according to market, spatial and temporal concentration.

- Data is collected and analysed over a ten year period from 2005 to 2014.

- 735 European airports are compared.

- Implications for impact/added value analysis are considered. 


\section{Introduction}

The liberalisation of air transport markets in Europe means that airlines have greater freedom to choose where they fly to and from, and generally set fares, frequencies, capacities and routes according to commercial considerations. This has provided opportunities for airports to grow and expand their services. However, it has also meant that airports are exposed to a greater degree of risk from changes that airlines may make to the services that they provide. In a turbulent environment such as this, airports should understand the extent to which they are dependent on a single source for most of their traffic and seek to reduce dependency where possible in order to minimise their exposure to risk.

Consider an airport which is doing well from a pure accounting and financial point of view but which is almost entirely dependent on a single city, country, airline operator or season for its traffic. This may cause problems from a dynamic point of view if the operator goes bankrupt, or decides to serve an alternative airport or make changes to the services that it provides at the airport. Likewise, the airport may suffer a major blow if the primary city/country served falls into a serious recession or if its government decides to publish advice against travelling to the area where the airport is located. Moreover, in case of strong seasonality of demand, the airport may be financially vulnerable to industrial action (e.g. strike of employees); disruption due to adverse weather conditions; or other unforeseen events occurring during the peak season. This means that in addition to exposure to economic trends in key markets, an airport that is dependent on a single city, country, airline operator or season for most of its traffic, will also be exposed to geopolitical and natural hazard events in both its key markets and its very location.

Changes in the concentration of traffic at airports as a result of liberalisation have been investigated by previous studies (e.g. Derudder and Witlox, 2009; Dobruszkes, 2009; Halpern, 2011; Papatheodorou and Arvanitis, 2009; Suau-Sanchez and Burghouwt, 2011). Developments in the relationship between airports and airlines as a consequence of liberalisation have also been investigated (e.g. Francis et al., 2003; Francis et al., 2004; Graham, 2013; Starkie, 2012). However, there has been little research on airport dependency per se. This is important to know from a strategic risk management perspective because of its ability to provide a 'new competitive edge' (Clarke and Varma, 1999) by measuring the degree of market, spatial and temporal concentration at an airport. The measurement of airport dependency can provide insight on the sustainability and worthiness of financing airport projects and on whether airports should diversify further their activities by investing in the growth and expansion of their network. It may also help identify whether there is a case for any state subsidy, which is particularly relevant today, given the European Commission's adoption of new stricter guidelines for state aid to airports in 2014 (EC, 2014a).

This paper provides an important methodological contribution to how concentration can be measured in the context of airport dependency. As will be discussed in this paper, there is a need for stronger techniques in this area that enrich those already in use. This paper meets that need by creating an innovative and focused measure called the Airport Dependency Index (ADI). This paper also provides an example of how the ADI can be applied to European airports. Section two presents the background to the study with a focus on the liberalisation of air transport markets in Europe, the dependency consequences for airports, and how such dependency can be measured. Section three outlines the methodological approach taken including the selection of airports, data sources and construction of the ADI. Section four discusses the main 
research findings of the study. Finally, section five provides a conclusion including policy and management implications and recommendations for future research.

\section{European liberalisation and the airport dependency issue}

Varying degrees of liberalisation of European air travel markets have occurred with a number of different developments. Intra-European airline liberalisation was achieved through three packages introduced in 1987, 1990, and between 1993 and 1997 (EC, 2007). Externally, a more liberal environment has resulted from Europe negotiating horizontal or other agreements on certain aspects of air services with about thirty individual states, and there remain open negotiations or agreements pending signature with many more (EC, 2014b). Furthermore, Europe has signed a horizontal agreement with the West African Economic and Monetary Union in 2009 - the first horizontal agreement regarding air services with another regional organisation (EC, 2009). Perhaps most significantly, Europe negotiated three bilateral conventions with Morocco, Canada and the US during the 2000s (EC, 2014c). The vision for these socalled 'open skies' agreements is that traffic rights will be liberalised gradually so that a fully Open Aviation Area is established that is similar to Europe's internal market. In addition, an aviation summit to enhance cooperation between the EU and the Association of Southeast Asian Nations (ASEAN) has already been held in 2014, and the ultimate objective is to create an EU-ASEAN open skies agreement (EC, 2014d).

Turning to the airport industry, the sector in Europe was traditionally characterised by public sector ownership and national requirements (Graham, 2014). However, at the same time as Europe's internal air transport market was being liberalised, a number of governments in Europe began to transfer the ownership or operation of larger airports to the private sector. Many smaller airports in Europe are still publicly owned but the majority is now operated by corporatised entities. Overall in 2010, over 20 per cent of airports in Europe were privatised or operated as public-private partnerships, while 74 per cent of the remaining publicly owned airports were operated as corporatised entities (ACI-Europe, 2010).

Transformations in the way that airports are owned and operated mean that, just as airline decisions are driven more by commercial considerations, so too are the decisions of airports. Airports have relatively large fixed infrastructure costs but low marginal costs of processing extra passengers (Francis et al., 2003) who can provide additional revenue from commercial activities. This helps explain why it is so important for airports to seek growth and expansion. However, there are often investment needs associated with attracting new or expanded services, and the risk of investment is likely to be high given the relative freedom that airlines now have to enter and exit the market with aircraft that are effectively mobile assets. Airports on the other hand generally have sunk assets (Starkie, 2012), and are therefore vulnerable to reductions in traffic or the withdrawal of services altogether.

One of the main consequences of air transport liberalisation is that airlines have become more footloose, being freer to choose where they fly to and from, and this, along with sustained long-term growth in demand for air travel, has provided airports with increased opportunities to attract new routes but also challenges associated with retaining existing ones (Halpern and Graham, 2013). Moreover new types of airline business models such as low cost carriers (LCCs) have emerged as a consequence of liberalisation (Gilroy et al., 2005; Graham and Shaw, 2008; Mason et al., 2013). These have provided traffic growth for many secondary and regional airports (Francis 
et al., 2003). Nonetheless, the growth often comes from a single operator and therefore adds risk to the airport business.

Since low operating costs are a key characteristic of LCCs, the latter actively use their bargaining power to secure favourable deals at airports (Francis et al., 2004; Gillen and Lall, 2004). They are also more likely to make changes to routes or withdraw from an airport if they are not satisfied with the deal that they are getting. As a result, there is generally a high degree of churn on point-to-point routes in Europe (Bush and Starkie, 2014). In addition a number of larger LCCs in Europe, such as Ryanair and easyJet, are pan-European and operate from multiple bases. A complete withdrawal from a base is less likely because of the sunk costs that are associated with setting up a base. Nonetheless, withdrawal can happen, and LCCs do not hesitate to openly express their reasons for doing so, which may then add further pressure on the airport in terms of its ability to capture future business.

One of the more established airline business models in Europe is the leisure carrier offering mainly charter or non-scheduled services. These airlines traditionally offered airports, especially secondary or regional ones, the opportunity to grow their network despite serving smaller catchment areas than larger main airports. The problem with their type of operation is that it tends to be highly seasonal and therefore results in a temporal concentration of demand (Halpern, 2008). Major investment is often required to facilitate growth from leisure carriers at airports. Nonetheless, the inconsistent and uneven utilisation of the airport is likely to result in an inefficient use of resources and may not provide an adequate return on investment. LCCs are often viewed by secondary or regional airports with a high proportion of leisure traffic as being a good way of reducing seasonality of demand because of the scheduled, year round nature of their services. However, this is not always the case as LCCs may also operate scheduled services on a seasonal basis. Therefore many airports that had good relations with leisure carriers in the past face the difficult decision of whether to target LCCs in an effort to reduce seasonality and grow their business but risk losing their leisure customers as a result (Farmaki and Papatheodorou, 2015).

The traditional national carriers (and regional airlines that feed their networks or serve their own niche markets) have also reacted to the new and more competitive environment. Historically, they were bound to a hub airport by the regulation of routes and the network nature and geographic concentration of their business model means that they are generally less flexible than LCCs or leisure carriers. Their initial reaction was to strengthen their presence and that of their alliance partners at the hub airports. This meant that the latter were highly dependent upon a single operator or alliance group for most of their traffic (Dennis, 2005); nonetheless, for a number of airlines (such as SAS, Lufthansa, Air France/KLM and IAG: British Airways/Iberia) there is now a growing trend to use multiple hub airports (Bush and Starkie, 2014). Operating at multiple hub airports provides network carriers with the option to switch parts of their business between the different hubs.

In general, increased competition in the airline industry has increased the risk of airline failure, and a number of operators have experienced bankruptcy since the creation of the European air transport market. This includes operators of all types of airline business models such as the LCC Sterling Airlines of Denmark in 2008 and subsequently Cimber Sterling in 2012, and UK regional airline Air Southwest in 2011. Leisure carrier XL Airways went into administration in September 2008 (Parton and Ryley, 2012). A number of former national carriers have also failed in recent years. This includes Sabena of Belgium in 2001, Swissair of Switzerland in 2002, 
Malév Hungarian Airlines in 2012 and Cyprus Airways in 2015. The impact of airline failure on airports can be significant. For example, Malév was Budapest Airport's biggest airline customer serving over three million passengers annually. As a result of the collapse of Malév, Budapest Airport initially lost around 36 per cent of its total passengers and 39 per cent of all aircraft movements (Linkweiler, 2013).

Changes to services but also failure of an airline therefore pose a risk to airports, especially those that are almost entirely dependent on a single city, country, airline operator, or season for most of their traffic. Such airports are also likely to face risk of exposure to economic trends in key markets such as the impact of the global financial crisis of the late 2000s (Dobruszkes and Van Hamme, 2011), or geopolitical and natural hazard events such as the current Ebola virus epidemic in West Africa, the Arab Spring of revolutionary events that spread throughout the countries of the Arab League and its surroundings during the early 2010s, and eruptions of the Eyjafjallajökull volcano in Iceland in April 2010 (Mazzocchi et al., 2010).

Therefore the more turbulent and liberalised environment within which many European airports now operate means that it is important for them to diversify their business, especially in terms of reducing market, spatial and temporal concentration so that a problem with one city, country, airline operator or season can be compensated to some extent by continued or increased demand from other sources. In order for informed decisions to be made related to such strategies, an appropriate measure of airport dependency needs to be utilised. The next section compares the different measures which have previously been considered, and identifies their shortcomings, which provides the rationale for the use of the ADI.

\section{Methodology and operationalisation of the ADI}

According to the Merriam Webster Dictionary dependency is "the quality of being dependent", for instance, "decided or controlled by something else" and/or "needing someone or something else for support, help, etc." Though useful, this definition is not particularly enlightening at least from a methodological point of view. It does not provide any explicit hints on how to measure dependency in general and specifically in the context of airports. Moreover, a simple search on the Internet provides limited evidence on the existence of dependency indices per se with the age dependency ratio being one of the few exceptions. For this reason, it was decided to study methodological issues regarding three terms, which share common conceptual ground with dependency, namely (market) concentration; inequality; and specialisation.

In particular, market concentration occurs when a small number of sellers and/or buyers dominate the market; for instance, by controlling a large share of the production value- and/or quantity-wise. Inequality refers to unfair prevailing conditions among people regarding prosperity, access to education and professional opportunities. Specialisation refers to the allocation of production resources to a particular economic function usually in the context of comparative and/or competitive advantage. From an initial perspective, therefore, building on the theory of concentration indices to derive an airport dependency index makes good sense as dependency is largely about market share and control.

According to Hannah and Kay (1977), a good concentration index should meet the following seven criteria: (1) the concentration curve ranking criterion suggests that when the concentration curve of one industry is above that of another one, then the former should be characterised as more concentrated; (2) the sales transfer principle 
claims that the transfer of sales turnover from smaller to larger businesses should lead to an increase of the measured concentration; (3) the entry condition suggests that the entry of new companies of size below that of the average incumbent should lead to a reduction of the measured concentration, while the exit of businesses below that threshold should result in an increase in the measured concentration; (4) the merger condition suggests that mergers should result in an increase in measured concentration; (5) random brand switching should reduce concentration since more customers leave large incumbents in favour of smaller companies; (6) a smaller scale of entry should have a modest only effect on measured concentration compared to a larger scale of entry; and (7) Gibrat's Law suggests that random factors in the growth of businesses should increase the measured concentration.

Having the above in mind, Hannah and Kay (1977) as well as other authors (e.g. Lipczynski et al., 2009) argue that the Herfindahl-Hirschman Index (HHI) is one of the best candidate indices to measure concentration because it meets all the above criteria. The HHI is defined as the sum of squared market shares and ranges between zero (in case of a market with infinitesimal firms) and 10,000 (in case of a monopoly); values over 1,800 are usually indicative of a concentrated market (Papatheodorou and Arvanitis, 2009). Hannah and Kay (1977: 50-52) also stress that measures of inequality (such as the Gini coefficient to be discussed below) violate some of the axioms stated above and hence should not be used to measure seller concentration. As discussed in du Pisanie (2013), they claimed "that inequality and concentration are not the same thing" and "that trends in one do not necessarily shed light on trends in the other", arguing that "...the arguments above were laid out with great clarity and lucidity by Adelman (1951) all of twenty-five years ago, and that nevertheless economists have regularly continued to make unwarranted inferences about changes in concentration on the basis of measurements of inequality."

Building on the Hannah and Kay (1977) analysis Palan (2010) proposes good measures of regional specialisation using similar criteria termed as anonymity; the axiom of progressive transfers; the existence of bounds; the property of decomposability; classification and number of industries. Palan (2010) argues again in favour of the HHI and against measures of inequality (such as the Gini coefficient) as the latter make among others moral/fairness judgments irrelevant in regional studies, for instance, "... since unequal industry structures do not necessarily imply inequality of productivity and income, but can stem from different specialisation patterns all leading to the same level of income" (Palan, 2010: 7).

On the above grounds, if airport dependency were identified as airport concentration or specialisation then the HHI would have been a very good choice for the construction of the ADI. Nonetheless, and following the Reynolds-Feighan (1998) argumentation the Gini coefficient (in its relative form as explained later) was used instead; for instance, an inequality index was chosen over a concentration and/or specialisation index. In fact, the Gini index is a widely applied method in development economics to measure levels and spread of income disparity. It is also a useful tool for economic and transport geographers due to its ability to capture spatial dispersion. Consequently, the Gini index has been variously applied to measure the spatial evolution of air transport networks. In many air transport applications, the Gini is often used to assess the spatial impact of a significant shift in policy such as liberalisation and privatisation (Reynolds-Feighan, 2001; 2007).

According to Sen (1976) the Gini coefficient possesses interesting properties of dispersion and meets four essential axioms, namely monotonicity (e.g. when the 
traffic share of a lower-ranked airline is reduced then dependency at an airport level is increased); transferability (e.g. the shift of traffic away from a low-ranked airline and towards a high-ranked one will increase dependency); relative equity (e.g. if an airline has a smaller traffic quotient than another in a specific airport, then the importance of traffic reduction in the case of the former should be higher compared to that of the latter carrier); and ordinal rank weight (e.g. the weight on the market share gap between an airline and its successor in the traffic ranking of a specific airport is the same as for all other carriers with the same market share).

More importantly, however, and although unjustness is not an explicit feature of dependency, risk is. This is of essential importance when considering the zero output principle, which distinguishes measures of concentration from measures of inequality (Chakravarty, 1992). When a person with zero income is added into a population, concentration (as measured for example by the HHI) does not change but inequality does increase. Likewise, an airline operating at an airport with no passengers on its flights will have a zero market share and hence will not affect traffic concentration at the particular airport. From a risk management perspective, however, the very existence of that airline is important at least from a dynamic point of view: given that the airline has already incurred entry sunk costs and may wish to avoid market exit related costs, it has a genuine interest to raise its level of traffic thus also benefiting the airport. Similarly to the infant industry argumentation in strategic trade theory (Krugman, 1986), airports have good incentives to attract new carriers from different origins and/or make the incumbents increase their number of services during the offseason as such a strategy may payoff in the longer-term even though the short-term impact may be minimal.

In this context, the HHI may prove a poor measure of dependency as it is sizedependent and rather insensitive to the changes discussed above, for instance, at the lower-ranked units (Gaile, 1984; Reynolds-Feighan 1998). The Gini coefficient may be a better alternative as it is most sensitive to changes in the middle or lower part of the distribution. In addition, the Gini coefficient may prove to be of greater value when measured in relative (to encapsulate comparison with peers) but also in dynamic terms (to study the effect of time in delivering the desired strategic outcomes), as discussed later in the paper.

It seems, therefore, that there is a valid precedent for adopting the Gini index to develop the ADI. More specifically, this is now defined as a linearly additive combination of four sub-indexes of traffic concentration regarding cities, countries, airline operators and seasonality. Space is represented twice in the ADI: at a country level traffic concentration aims at addressing both economic and geopolitical issues while the city level aims to highlight potential regional gravity and/or location specific relationships as well as to encapsulate cases where a city is served by more than one airport thus avoiding the need to introduce an extra concentration sub-index at the airport level. The market is represented in the ADI by considering traffic concentration of flows from different carriers while (monthly) seasonality aims to capture the potential impact of extraordinary and/or unforeseen phenomena including 'black swan' events (Taleb, 2007), which have very important repercussions for strategic risk management. Having the above in mind, the ADI may be defined as:

$$
\begin{aligned}
& A D I_{k}=a \cdot f(\text { airlines })+b \cdot f(\text { cities })+c \cdot f(\text { countries })+d \cdot f(\text { seasonality }) \\
& \text { s.t. } a+b+c+d=1
\end{aligned}
$$


where ADI for an airport $k$ is the weighted combination of the four sub-indexes. Adopting a systems perspective, we assume that airports of different sizes serve different purposes; yet at each level a homogenous group of $k$ airports is assumed to exist. For example, there may be a group of large 'hub' airports and another related to regional and/or tourism airports that are possibly but not necessarily dependent on the hubs.

In order to operationalise the ADI two important decisions have to be made: first, the decision on how to specify the function, $f($.) for each sub-index; and second the decision on how to obtain the weights $a, b, c$ and $d$. With respect to the first, the suitability of the Gini coefficient has already been discussed. To achieve this objective, detailed scheduled data are required. We have used airline scheduled capacity data from the Capstats database (www.capstats.com) across ten years, 20052014 (inclusive). Such data are usually provided by airlines up to one year in advance of actualisation. Nonetheless, there are several important methodological issues that must be addressed in order to appropriately calculate the Gini coefficient.

The issues primarily relate to dealing with the changing number of nodes (denote this as $n$ ) in a network year-on-year. One method is to normalise the Gini index by fixing ' $n$ ' across time (e.g. Papatheodorou and Arvanitis, 2009). In this way, the confounding effects on Gini, of changes in airline network size (in terms of nodes connected), and the changes in the pattern of capacity distribution across the network, can be separated enabling the analyst to focus on the latter. We can easily see why the Gini score changes as a function of $n$. The theoretical maximum value of Gini increases as $n$ increases because the Gini index has a maximum value of $(n-1) / n$. In air transport network studies, it is unrealistic to have all traffic concentrated in one node as there have to be at least two. Thus, Burghouwt (2007) proposes an adjustment of the Gini index from $(n-1) / n$ to $(n-2) / n$, and uses this Gini-maximum as a normalisation variable (ActualGini/GiniMax). However, the theoretical maximum (which is $1-2 / n$ ) rapidly approaches 1 as $n$ grows. Thus, for applications involving large airports (with a large network) the normalisation does not change the result in an important way.

In spite of the differences in the way the Gini is used, previous approaches share a feature that is potentially very limiting for the development of the ADI: applications have used the uniform distribution as a benchmark. There are two potential problems with this approach. First, for the ADI, the uniform distribution is a potential problem because an airport with equally-distributed traffic across ten cities yield the same Gini index value as an airport with only two equally-distributed cities (Gini $=0$ in both cases), for instance, both ADIs will be zero indicating zero dependency, and by implication, zero risk. Arguably, though, the latter is exposed to greater risk and this should be reflected in a higher dependency index. Second, under the uniform distribution formulation, the Gini is not conditioned on the actual characteristics of air transport distribution. Nonetheless, it may be desirable for a dependency measure to be sensitive to the characteristics of $n$. For instance, under the uniform distribution, the Gini score on the two-node case will be identical to another two-node case as long as the flights are distributed equally across the two nodes. However, an equal distribution across two nodes, which includes Paris and London, may be of considerably different risk profile compared with an equal distribution between London and Trondheim.

One way to go about accounting for some of these differences may be to replace the uniform distribution with the industry's 'natural base line'. It is more informative to examine how an airport's flight distribution characteristics deviate from the 'grand 
mean' than to compare the distribution against a purely theoretical criterion (i.e. zero). This can be done by using the relative Gini. More specifically, this may be expressed as:

$$
G_{k}=1-\sum_{n=1}^{N} w_{j}\left[w_{j(n)}^{k}+w_{j(n-1)}^{k}\right]
$$

where $G_{k}$ denotes the relative Gini index value of airport $k, n$ is the node/area connected to the airport, $N$ is the total number of nodes/areas, $w_{j(n)}^{k}$ is the cumulative share of $n^{\text {th }}$ node of airport $k$ for node $j$, and $w_{j}$ is the industry share of the node/area $j$. The drop in the subscript $k$ suggests that it is a sum across all $k$ airports. In most air transport applications $w_{j}=1 / N$ which is a uniform distribution.

In order to overcome the first issue outlined above with respect to the uniform distribution, we need to choose a fixed $N$. A reasonable strategy might be to use the total number of nodes in the sample airports. Thus, if airport A and B have 30 nodes and 50 nodes, respectively, and 20 of them are linked to both $\mathrm{A}$ and $\mathrm{B}$, then $N$ will be 60 resulting from 10 (exclusive to $\mathrm{A})+20$ (overlapping distribution of $\mathrm{A}$ and $\mathrm{B})+30$ (exclusive to B). It is clear that in the event that traffic is equally distributed across the nodes, using the approach above will result in the Gini score of the airport with a lower number of nodes being higher than the score of an airport with more nodes. This happens because the former airport in the example has more zeros in the distribution compared to the latter airport. This achieves the desired result from the ADI perspective, for instance, in an event of equal distributions, the ADI will be greater for an airport serviced by two airlines than an airport with many airlines.

To remedy the issue with respect to the characteristics of $n$, we need to choose an alternative weighting index other than $1 / N$. Instead of a theoretical baseline (i.e. the uniform distribution), the present approach uses an empirical baseline obtained from the sample airports. This means that the uniform distribution is replaced by a weight, for instance, $w_{j}=\sum_{1}^{k} w_{j}$ as also suggested by Combes et al. (2008). The weighting vector is the industry share of each city, country, airline or month for a given year. The year is pre-determined by the analyst and the share is estimated based on an average from a selected sample of airports. Thus, using 2014 as the baseline year, the relative Gini allows us to answer questions like: "relative to the 2014 industry average, what is the dependency of airport $\mathrm{X}$ in 2006 compared to airport $\mathrm{Y}$ in 2010?"

With respect to the second operationalisation issue (the generation of weight coefficients $a, b, c$ and $d$ in equation 1), this is of critical importance as by definition the ADI is highly dependent on the actual weights used as is the case with every composite indicator (Moreira et al., 2012). Booysen (2002) points out that composite indicators have a number of limitations including selection bias and lack of clear rationale behind weighting. On the other hand, Saisana and Tarantola (2002) highlight the advantages of composite indicators including the derivation of a simple measure without losing basic information. In the present case, an expert opinion survey was used to derive the weights for the sub-indexes. An online survey was developed to obtain Likert scores on the extent to which the respondent feels an airport's vulnerability is affected by the number or type of cities, countries, operating airlines the airport serves, and the seasonality of demand. Respondents were recruited by multiple means, including through posts on the Air Transport News website (www.atn.aero) and selected groups on LinkedIn, as well as appealing to the existing industry networks developed through previous projects. A copy of the survey is available from the authors upon request. 143 full responses were obtained between 
September and October 2014. All respondents identified air transport as their main industry. The average Likert score for each item was then calculated. After a minor adjustment to ensure that the weights sum to one, the following weights were assigned to each sub-index: city (0.254); country (0.281); airlines (0.219); and seasonality (0.246).

Using the Capstats database, 735 airports were identified as active for at least one year throughout the ten-year period under consideration, 2005 to 2014 (inclusive). The total number of active airports in 2014 (baseline year) was 607. These were subsequently classified into five airport groups according to the 2014 world traffic capacity offered by their hosted airlines in Available Seat Kilometres (ASKs). Group 1 comprises 15 airports exceeding 25 billion ASKs. This group includes among others all major European hub airports serving the three major strategic alliances: London Heathrow (LHR) and Madrid Barajas (MAD), which are hubs of the International Airlines Group, the holding company of British Airways and Iberia, leading the oneworld alliance in Europe; Frankfurt Airport (FRA), which is the main hub of Lufthansa and the Star Alliance in Europe; and Paris Charles de Gaulle (CDG) and Amsterdam Schiphol (AMS), which are the major hubs of Air France - KLM, as well as of the SkyTeam alliance in the Old Continent. Istanbul Airport (IST) is another major contributor in Group 1 hosting the extensive network of Turkish Airlines. Group 2 comprises 43 airports with between 5 and 24.9 billion ASKs. This group includes secondary hubs like Milan Malpensa (MXP) and Vienna (VIE) but also major regional/leisure traffic airports such as Palma de Mallorca (PMI) in Spain; Larnaca (LCA) in Cyprus; and Antalya (AYT) in Turkey. The latter largely cater for European sunlust tourists and hence exhibit peak traffic flows during the summer season. Group 3 consists of 43 airports with between 2 and 4.9 billion ASKs; Group 4 refers to 100 airports with between 0.5 and 1.9 billion ASKs. All Group 1-4 airports were active throughout the ten-year period. Finally, the largest by number Group 5 consists of 406 airports with less than 0.5 billion ASKs.

Relative Gini sub-indexes (based on equation 2) and the ADI (based on equation 1) have been calculated for all airports under consideration. Further to an initial presentation of descriptive statistics, the following section reports empirical results at three levels. First, spider diagrams related to airport Groups 1-3 show the evolution of ADIs between 2005 and 2014 in a visual manner. For Group 1 airports the spider ADI diagram based on the standard (uniform) Gini sub-indexes is also produced for comparison purposes. In all cases, ADI values in 2005 are ranked clock-wise in an increasing dependency order; the corresponding ADI values for years 2008, 2011 and 2014 are then superimposed. Visually, this enables quick identification of the dependency rank as well as the straightforward identification of the airports with greatest changes in dependencies. Second, the relationship between airport size and ADIs is tested using a fixed effects panel regression method; its results are reported in both tabular and diagrammatic form. Finally, another regression highlights the effect of weight choice on the ADI; the results are shown in tabular form.

\section{Results and discussion}

Table 1 shows descriptive statistics of the five airport groups in 2014. Three major observations can be made. First, airport traffic at European airports seems to be largely concentrated; illustratively, the average capacity size of a Group 1 airport (in terms of ASKs) is 50 per cent larger than the capacity of all 406 Group 5 airports together. Second, the mean ADI value is inversely related to capacity size meaning that larger airports seem to face a lower dependency compared to smaller ones. This is 
an important issue treated more formally (in the context of a regression analysis) later in this section. Third, the ratio between the mean ADI value and its standard deviation is larger at small airports - the latter are characterised by somewhat similar levels of dependency compared to larger airports.

Table 1

Descriptive statistics of the five airport groups in 2014.

\begin{tabular}{|c|c|c|c|c|c|}
\hline & \multicolumn{5}{|c|}{ Airport group } \\
\hline & 1 & 2 & 3 & 4 & 5 \\
\hline Number of airports & 15 & 43 & 43 & 100 & 406 \\
\hline Mean ASK & 63.9 billion & 10.2 billion & 3.05 billion & 1.07 billion & 0.1 billion \\
\hline St. Dev. ASK & 48.6 billion & 5.30 billion & 0.81 billion & 0.43 billion & 0.12 billion \\
\hline Mean ADI & 0.48 & 0.54 & 0.62 & 0.67 & 0.76 \\
\hline St. Dev. ADI & 0.07 & 0.07 & 0.07 & 0.06 & 0.06 \\
\hline
\end{tabular}

Turning now to the diagrammatic analysis, in Fig. 1 we can see that for all Group 1 airports dependency is reduced over time albeit not dramatically. Frankfurt (FRA) has the lowest dependency (in spite of its explicit association with Lufthansa) and this has not changed much over the period 2005-2014. Moreover, Madrid (MAD) and Barcelona (BCN) have experienced the greatest decrease in dependency over the tenyear period. Fig. 2 shows empirically that the relative Gini encapsulates the yearly ADI change in a way that the uniform Gini does not. Relative Gini is thus able to develop a more nuanced understanding of each airport's level of concentration/dispersion especially at a composite index level.

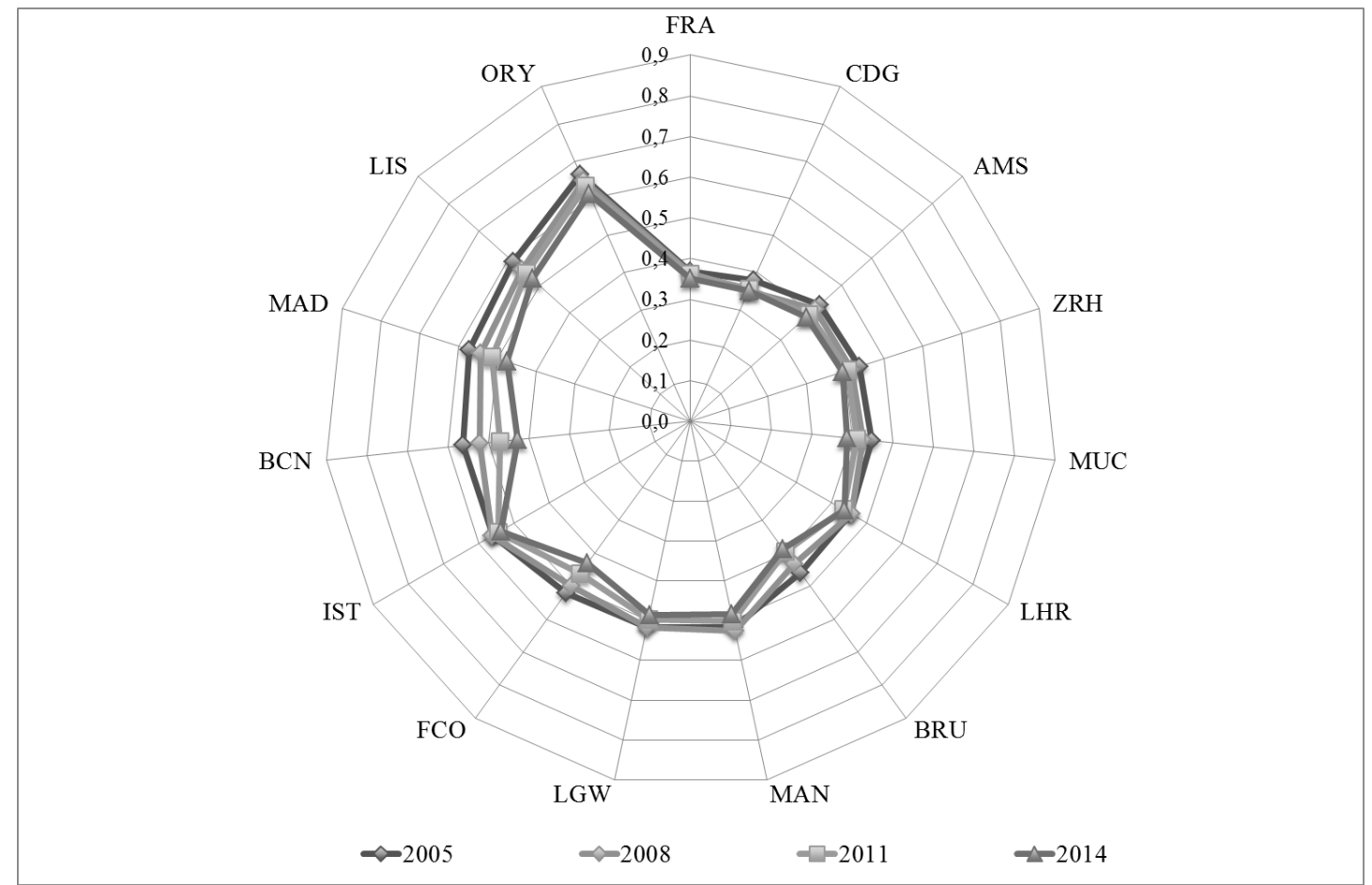

Fig. 1. Evolution of ADIs between 2005 and 2014 (15 Group 1 airports, relative Gini).

Note. AMS: Amsterdam - Schiphol; BCN: Barcelona; BRU: Brussels - National; CDG: Paris - Charles De Gaulle; FCO: Rome - Fiumicino; FRA: Frankfurt International; IST: Istanbul - Ataturk; LGW: London - Gatwick; LHR: London - Heathrow; LIS: Lisbon; MAD: Madrid - Barajas; MAN: Manchester International; MUC: Munich Franz Josef Strauss; ORY: Paris - Orly; ZRH: Zurich. 


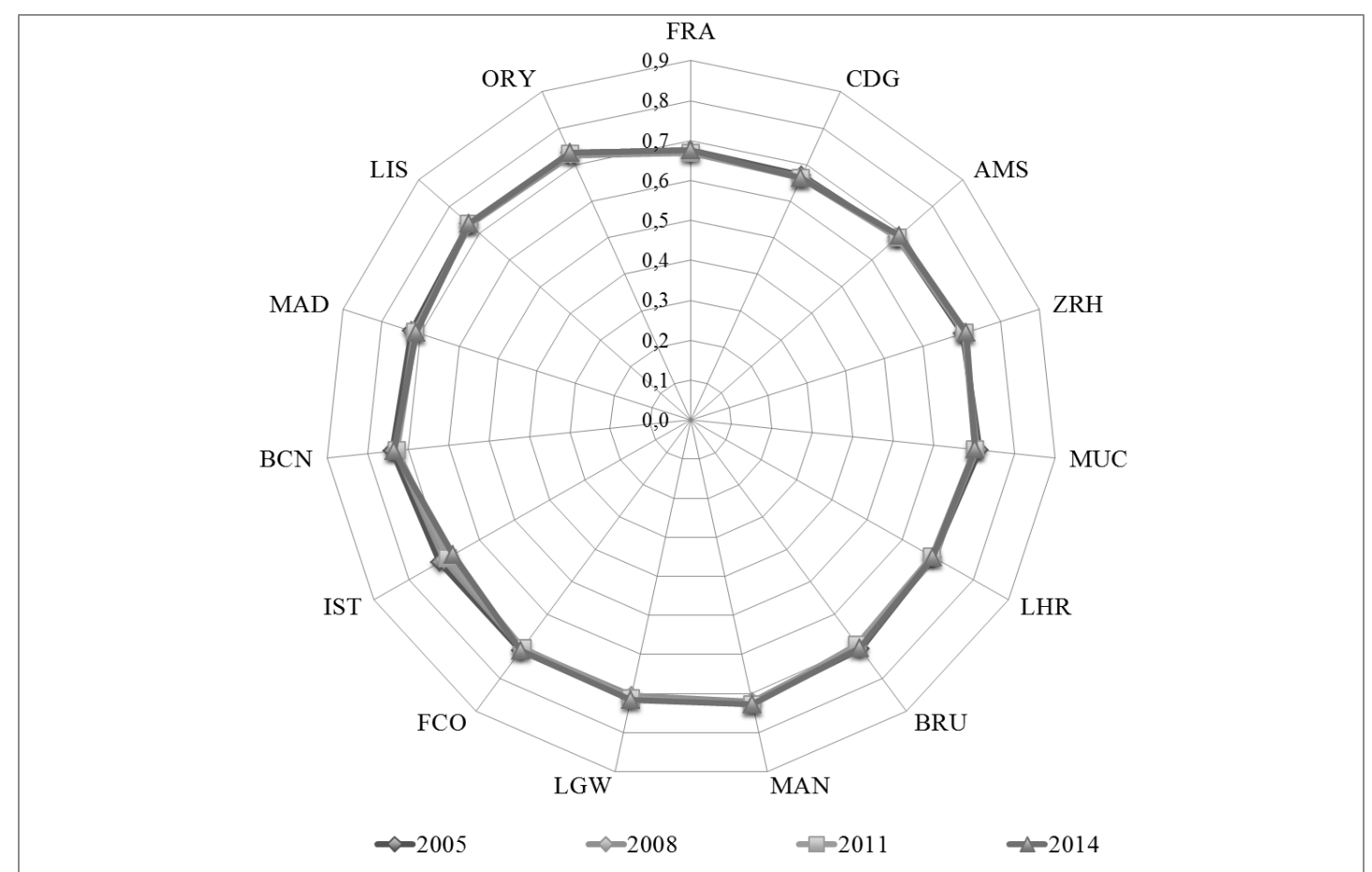

Fig. 2. Evolution of ADIs between 2005 and 2014 (15 Group 1 airports, uniform Gini).

Note. AMS: Amsterdam - Schiphol; BCN: Barcelona; BRU: Brussels - National; CDG: Paris - Charles De Gaulle; FCO: Rome - Fiumicino; FRA: Frankfurt International; IST: Istanbul - Ataturk; LGW: London - Gatwick; LHR: London - Heathrow; LIS: Lisbon; MAD: Madrid - Barajas; MAN: Manchester International; MUC: Munich Franz Josef Strauss; ORY: Paris - Orly; ZRH: Zurich.

In Fig. 3, we can see that Malaga (AGP), Palma de Mallorca (PMI), Tenerife South (TFS), Fuerteventura (FUE) and Istanbul Sabiha Gokcen (SAW) are the stand out performers with respect to decreasing dependency in the second group of airports. More specifically, Budapest (BUD) is the airport with the lowest level of dependency in Group 2; this is noteworthy given the collapse of Malév in 2012 and the subsequent sharp reduction in traffic as other carriers moved in to fill the market gap of the flag carrier thus leading to an even lower level of dependency in 2014. Istanbul Sabiha Gokcen (SAW) is also an interesting example of an airport benefiting from regional airport specialisation to reduce dependency, as many LCCs prefer to fly there as an alternative to Istanbul Ataturk (IST). Palma de Mallorca's (PMI) performance can be attributed to its diversification with respect to airlines and city network. Bergamo (BGY), on the other hand, experienced increasing dependency unlike the great majority of airports in Group 2. This may be attributed to the overwhelming and increasing presence of Ryanair at Bergamo (BGY). 


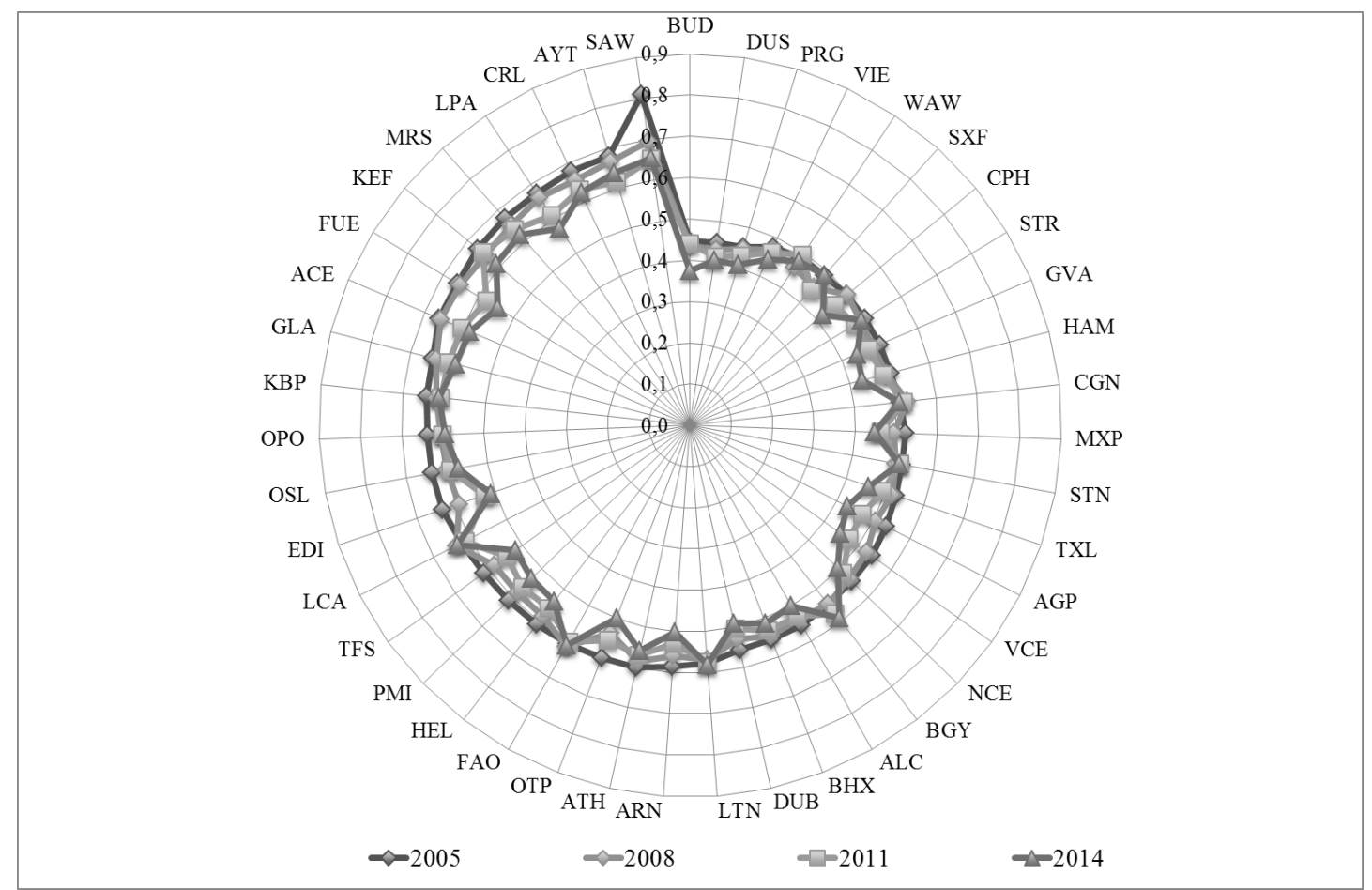

Fig. 3. Evolution of ADIs between 2005 and 2014 (43 Group 2 airports, relative Gini).

Note. ACE: Lanzarote; AGP: Malaga; ALC: Alicante; ARN: Stockholm - Arlanda; ATH: Athens - Eleftherios Venizelos International; AYT: Antalya; BGY: Bergamo - Orio Al Serio; BHX: Birmingham International; BUD: Budapest - Ferihegy; CGN: Cologne Bonn; CPH: Copenhagen; CRL: Brussels South Charleroi; DUB: Dublin; DUS: Dusseldorf; EDI: Edinburgh; FAO: Faro; FUE: Fuerteventura; GLA: Glasgow International; GVA: Geneva Cointrin; HAM: Hamburg; HEL: Helsinki-Vantaa; KBP: Kiev - Boryspol; KEF: Reykjavik - Keflavik

International; LCA: Larnaca; LPA: Las Palmas - De Gran Canaria; LTN: London - Luton; MRS: Marseille; MXP: Milan - Malpensa; NCE: Nice - Cote D'Azur; OPO: Porto; OSL: Oslo; OTP: Bucharest - Henri Coanda International; PMI: Palma de Mallorca; PRG: Prague - Ruzyne; SAW: Istanbul - Sabiha Gokcen; STN: London Stansted; STR: Stuttgart; SXF: Berlin - Schoenefeld; TFS: Tenerife South; TXL: Berlin - Tegel; VCE: Venice Marco Polo; VIE: Vienna International; WAW: Warsaw - Frederic Chopin.

Fig. 4 exhibits similar patterns to Fig. 3. In particular, for the majority of airports in Group 3, dependency seems to have decreased over time. Pisa (PSA) appears as the least and Bergen (BGO) as the most dependent airport; the latter is followed by Heraklion (HER) and Rhodes (RHO) in Greece, which exhibit very high levels of dependency due to the strongly seasonal character of flights in the tourism islands of Crete and Rhodes respectively. Ibiza (IBZ) has managed to substantially reduce its dependency possibly due to the active efforts undertaken not only to differentiate its incoming traffic but also to reduce the seasonality of its tourism destination product. 


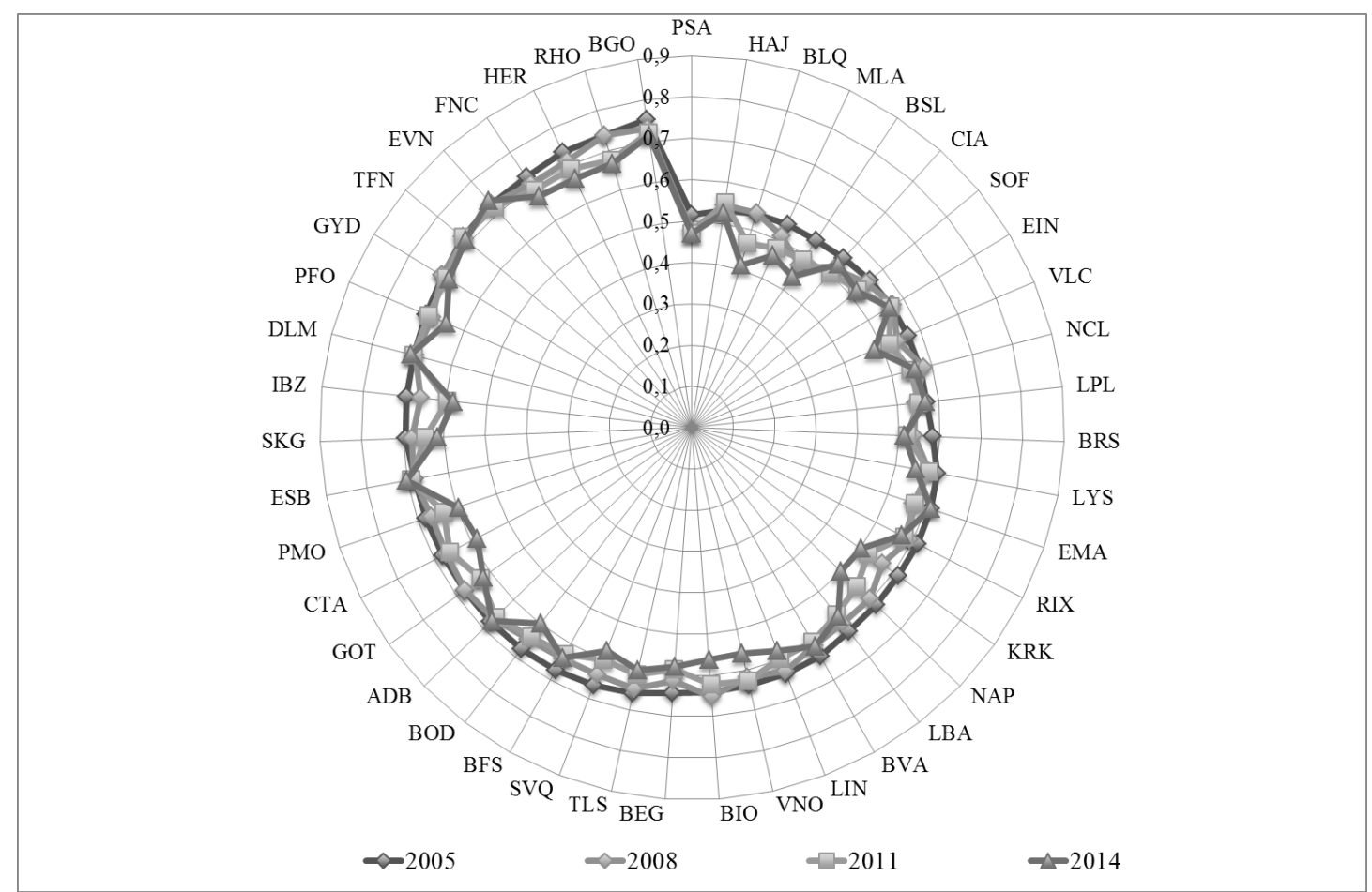

Fig. 4. Evolution of ADIs between 2005 and 2014 (43 Group 3 airports, relative Gini).

Note. ADB: Izmir - Adnan Menderes; BEG: Belgrade - Nikola Tesla; BFS: Belfast International; BGO: Bergen Flesland; BIO: Bilbao; BLQ: Bologna - Guglielmo Marconi; BOD: Bordeaux; BRS: Bristol; BSL: Euro BaselMulhouse-Freiburg; BVA: Paris - Beauvais; CIA: Rome - Ciampino; CTA: Catania - Fontanarossa; DLM: Dalaman; EIN: Eindhoven; EMA: East Midlands; ESB: Ankara - Esenboga; EVN: Zvartnots International; FNC: Madeira; GOT: Gothenburg - Landvetter; GYD: Baku - Heydar Aliyev International; HAJ: Hanover; HER: Heraklion - N. Kazantzakis; IBZ: Ibiza; KRK: Krakow-Balice; LBA: Leeds/Bradford; LIN: Milan - Linate; LPL: Liverpool John Lennon; LYS: Lyon - Saint Exupery; MLA: Malta International; NAP: Naples; NCL: Newcastle; PFO: Paphos International; PMO: Palermo - Punta Raisi; PSA: Pisa; RHO: Rhodes International; RIX: Riga; SKG: Thessaloniki International; SOF: Sofia; SVQ: Sevilla - San Pablo; TFN: Tenerife North; TLS: Toulouse - Blagnac; VLC: Valencia; VNO: Vilnius International;

Further to the diagrammatic analysis and based on the observations made in Table 1, the relationship between airport size, time and the relative Gini sub-indexes and ADI is tested using a fixed effects panel regression method. As an independent variable, we have included airport size (in seats) and time dummies with 2005 as the base year. To avoid confusion, it is important to clarify that the choice of seats is justified by the fact that the ADI is also calculated based on seat capacity (ASKs are only used for the grouping criterion of airports in the diagrammatic analysis). Thus, the choice of seats is for the sake of consistency in the underlying metric. Besides, seats and ASKs are very strongly correlated $(\mathrm{r}=0.92)$, hence no real difference is expected in the econometric results. Second, the choice of 2005 as the base year refers solely to the regression per se - it is very typical in fixed effects panel regression analysis to use the first year in the time-series as the reference (base) year. On the other hand, the relative Gini sub-indexes and the ADI have been calculated using industry averages based on year 2014 as explained and discussed previously.

The results of the regression analysis are presented in Table 2. The sample size is 735 , which is the total number of airports that received services at least once in the period 2005-2014. The F-statistic is robust enough to validate the overall econometric significance of the models. The R-square values (calculated as the squared correlation between the actual and fitted values, as per Cameron and Trivedi, 2005) are also within acceptable range in the great majority of cases. According to the results, the airline Gini sub-index is not significantly affected by airport size. In other words, an airport's dependency on an airline is independent of its size - large airports are just as dependent on airlines as small airports are. Nonetheless, this possibly surprising result 
does not necessarily mean that scale of operations does not matter. In fact, the result may mask counteracting paths regarding strategic airport expansion choice. In particular, large airports (and/or those with an ambition to grow aggressively) may seek a strategic airline partner, for instance, a major network carrier or LCC which will use the airport under consideration as a major hub/base setting also the fundamentals for vertical governance (subject to regulatory approval). Typical examples of this strategy include Amsterdam Schiphol Airport and Brussels South Charleroi Airport. Alternatively, large airports may prefer to grow organically by diversifying their airline clientele. This seems to be the case at London Gatwick Airport, which traditionally relied on a large number of charter carriers but has diversified with growth also from LCCs. On the other hand, small airports are likely to depend only on a limited number of airlines given the thin nature of their traffic.

The situation regarding smaller airports also seems to be supported by the fact that country, city and season Gini sub-indexes are significantly and negatively affected by size. For instance, smaller airports have a greater dependency with respect to country and city (geographical dependency). This means that smaller airports are more susceptible to a geographically isolated shock such as in the main country and/or city served. As three out of the four sub-indexes comprising the ADI are significantly and negatively affected by size, it is not surprising that the ADI itself exhibits similar behaviour.

Moreover, in their great majority the time dummy variables are significant showing an increasingly negative impact on the ADI and the Gini sub-indexes (with the exception of seasonal dependency, which does not appear to be statistically important). In other words, the effect of time on ADI and the Gini sub-indexes increases as the year approaches 2014, the weight year. The pattern of increasing 'marginal effect of time' is a statistical artefact of the relative Gini. Relative Gini decreases if the pattern of distribution of a given year converges towards an industry average. Thus, for most airports the relative Gini will decrease as it gets closer to 2014. Even though the downward trend may be an artefact of the method, the rate and size of the changes are not. For example, the global financial crisis (years 2008 and 2009) had an effect of slowing down the rate of declining dependency. As shown in Fig. 5, this is evident by the "flat" 2008 and 2009 coefficients in what is otherwise a convincing downward trend. This is probably because there has not been much growth in airports during the crisis.

To step forwards and to estimate how much the base weight choice determines the pattern of relative Gini, the 2005 ADI values were calculated for all 735 airports using all 2005 to 2014 weight years. In other words, 10 different versions of 2005 ADI values were produced. We used panel data fixed effects method to regress these ADI values on the weight year. As shown in Table 3, the results exhibit an expected downward trend but the size of this is negligible (in the three decimal places). Thus, we conclude that the choice of weight year does not change our interpretation of the relative Gini; our conclusion is robust to the choice of the year from which we derived the industry average. 
Table 2

Impact of airport size and time on ADI and the Gini sub-indexes.

\begin{tabular}{|c|c|c|c|c|c|c|c|c|c|c|c|}
\hline & & \multicolumn{2}{|l|}{ ADI } & \multicolumn{2}{|l|}{ Airline } & \multicolumn{2}{|l|}{ Country } & \multicolumn{2}{|l|}{ City } & \multicolumn{2}{|l|}{ Season } \\
\hline Samples size & & \multicolumn{2}{|l|}{735} & \multicolumn{2}{|l|}{735} & \multirow{2}{*}{\multicolumn{2}{|c|}{735}} & \multirow{2}{*}{\multicolumn{2}{|c|}{735}} & \multirow{2}{*}{\multicolumn{2}{|c|}{735}} \\
\hline \multicolumn{6}{|l|}{ R-square } & & & & & & \\
\hline -within & & \multicolumn{2}{|l|}{0.041} & \multicolumn{2}{|l|}{0.16} & \multicolumn{2}{|l|}{0.078} & \multicolumn{2}{|l|}{0.095} & \multicolumn{2}{|l|}{0.003} \\
\hline -between & & \multicolumn{2}{|l|}{0.363} & \multicolumn{2}{|l|}{0.27} & \multicolumn{2}{|l|}{0.39} & \multicolumn{2}{|l|}{0.5} & \multicolumn{2}{|l|}{0.06} \\
\hline F-stats (p-value) & & \multicolumn{2}{|l|}{$9.19(0.000)$} & \multicolumn{2}{|c|}{$18.53(0.000)$} & \multicolumn{2}{|c|}{$11.57(0.000)$} & \multicolumn{2}{|l|}{$10.33(0.000)$} & \multicolumn{2}{|l|}{$1.89(0.043)$} \\
\hline Variables & & coefficient & t-ratio & coefficient & t-ratio & coefficient & t-ratio & coefficient & t-ratio & coefficient & t-ratio \\
\hline Airport size (seats) & & $-5.91 \mathrm{E}-09 * *$ & -2.19 & $-1.81 \mathrm{E}-09$ & -1.02 & $-7.29 \mathrm{E}-09 * *$ & -2.19 & $-6.32 \mathrm{E}-09 * * *$ & -2.59 & $-7.55 \mathrm{E}-09 * *$ & -2.14 \\
\hline \multirow[t]{9}{*}{ Time (base 2005) } & 2006 & -0.0019 & -1.05 & -0.0008 & -1.29 & $-0.0033 * * *$ & -3 & -0.0012 & -1.51 & -0.0022 & -0.31 \\
\hline & 2007 & $-0.0033^{*}$ & -1.65 & $-0.0023 * * *$ & -2.78 & $-0.0085^{* * *} *$ & -6.06 & $-0.0042 * * *$ & -4.03 & 0.0025 & 0.31 \\
\hline & 2008 & $-0.0051 * *$ & -2.42 & $-0.0056 * * *$ & -5.61 & $-0.0072 * * *$ & -4.39 & $-0.0034 * * *$ & -3.06 & -0.0039 & -0.49 \\
\hline & 2009 & $-0.0038 * *$ & -1.87 & $-0.0086 * * *$ & -7.41 & $-0.0097 * * *$ & -5.47 & $-0.0039 * * *$ & -3.33 & 0.0073 & 0.96 \\
\hline & 2010 & $-0.0092 * * *$ & -4.73 & $-0.0124 * * *$ & -9.38 & $-0.0139 * * *$ & -7.15 & $-0.0062 * * *$ & -4.55 & -0.0041 & -0.57 \\
\hline & 2011 & $-0.0106 * * *$ & -4.89 & $-0.0149 * * *$ & -9.98 & $-0.0159 * * *$ & -7.1 & $-0.0082 * * *$ & -5.6 & -0.0033 & -0.43 \\
\hline & 2012 & $-0.0106 * * *$ & -4.76 & $-0.0179 * * *$ & -10.59 & $-0.0171 * * *$ & -7.15 & $-0.0091 * * *$ & -5.93 & 0.0016 & 0.21 \\
\hline & 2013 & $-0.0116 * * *$ & -4.85 & $-0.0214 * * *$ & -11.78 & $-0.0197 * * *$ & -7.65 & $-0.0114 * * *$ & -6.99 & 0.0061 & 0.76 \\
\hline & 2014 & $-0.0161 * * *$ & -6.7 & $-0.0241 * * *$ & -11.95 & $-0.0206^{* * *}$ & -7.47 & $-0.0124 * * *$ & -6.95 & -0.0078 & -0.96 \\
\hline
\end{tabular}

Notes. Significance levels: * $10 \%, * * 5 \%, * * * 1 \%$.

$\mathrm{R}$-square-within is the square of the correlation between the actual and fitted values of the dependent variable (y), ignoring the contribution of the estimated airport-specific effects (i.e. $\operatorname{corr}^{2}\left(y_{k t}-\bar{y}_{k}\right),\left(X_{k t} \hat{\beta}-\bar{X}_{k} \hat{\beta}\right)$ where $k$ is airport and $t$ is time).

$\mathrm{R}$-square-between is $\operatorname{corr}^{2}\left(\bar{y}_{k}, \bar{X}_{k} \hat{\beta}\right)$ (Cameron and Trivedi, 2005). 


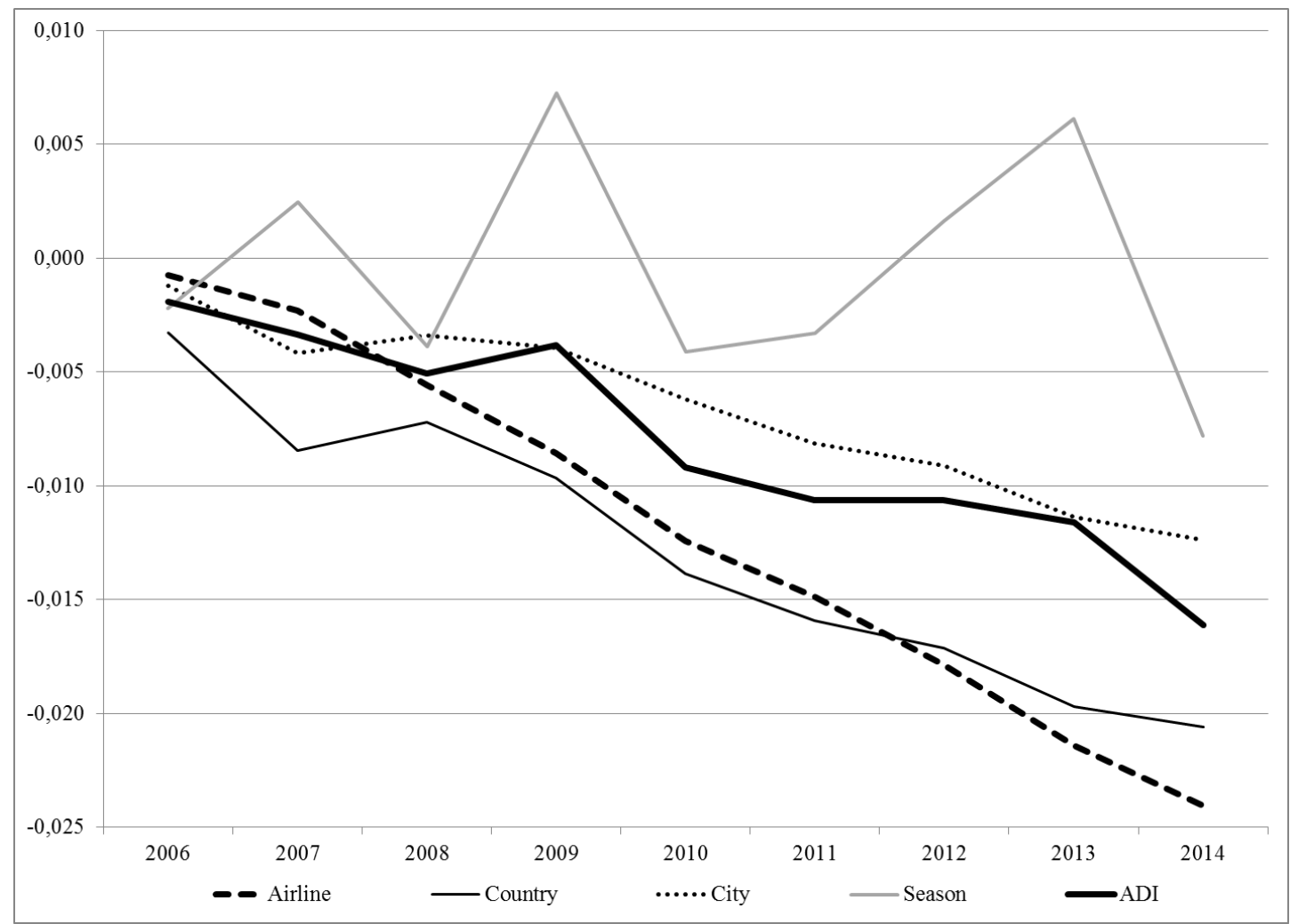

Fig. 5. The marginal effect of time on ADI and its constituents.

Table 3

The effect of weight year chosen on ADI.

\begin{tabular}{lcll}
\hline Variable & Year & Coefficient & t-ratio \\
\hline Time (base 2005) & 2006 & $-0.0009 * * *$ & -14.3 \\
& 2007 & $-0.0021 * * *$ & -13.36 \\
2008 & $-0.0034 * * *$ & -15.5 \\
2009 & $-0.0034 * * *$ & -13.56 \\
2010 & $-0.0054 * * *$ & -18.2 \\
2011 & $-0.0051 * * *$ & -14.25 \\
2012 & $-0.0066 * * *$ & -16.62 \\
2013 & $-0.0074 * * *$ & -17.35 \\
& 2014 & $-0.0073 * * *$ & -15.92 \\
\hline
\end{tabular}

Note. Significance levels: * $10 \%, * * 5 \%, * * * 1 \%$.

\section{Summary and conclusions}

As a result of the liberalisation process across the aviation supply chain, the corporate environment in the airport sector is no longer stable: risk and uncertainty have emerged at different levels and given the sunk cost nature of the related infrastructure, airport managers are more anxious to increase efficiency and performance as never before. From a strategic risk management perspective, airport managers need to develop an integrated framework to cater for both exogenous and endogenous threats but also opportunities (Hagigi and Sivakumar, 2009). In this context, this paper developed a composite index called the ADI to measure airport dependency based on the concept of the relative Gini coefficient.

The proposed ADI has a number of limitations. In particular, from a conceptual perspective and in spite of the fact that space is represented at two levels (country and city), a number of spatial issues such as airline global network dynamics (Mack et al., 2007; O'Connor, 2003), airport catchment areas and airport substitutability (Fuellhart, 2003) remain untouched. Moreover, and from a technical point of view, the relative 
Gini index replaces the uniform distribution $\left(w_{j}=1 / N\right)$ with the weighting vector $w_{j}=\sum_{1}^{k} w_{j}$. This weight in the relative Gini is derived from industry-level weighted average share, which in turn are estimated by the sample airport average share. This means that the efficacy of the relative Gini index relies on the selection of the sample airports. This could be a problem if, for instance, one of the airports is substantially larger than the rest, resulting in the one airport having too much influence on the calculation of the weight, which is used as a baseline to measure the level of airport dependency. This issue can be overcome by specifying homogenous within-group airports and/or by increasing airport sample size. In our analysis, this has been achieved by grouping the airports according to their ASKs. Furthermore, for the panel data analysis, the use of large sample size (735 airports) ensured that the weight is not undermined by a small group of very large airports. Nonetheless, in subsequent work, analysts must ensure that the sample of airports are carefully selected.

In any case, it is believed that the ADI provides an interesting methodological innovation in terms of furthering the existing theory on the concept of the relative Gini coefficient as well as in terms of constructing a composite index for airports to simultaneously consider different facets of traffic flows. Moreover, the ADI may assist airport managers in shaping their strategies. First, the ADI may prove an interesting tool in the context of comparative analysis as soon as some consensus is reached (possibly in the context of future research) with respect to the optimal mix of network connectivity. Traditionally, benchmarking has been usually undertaken in the context of Data Envelopment Analysis (DEA) (e.g. see Gillen and Lall, 1997) and Stochastic Frontier Analysis (SFA) (e.g. see Scotti et al., 2012). Both techniques are valid and have been fruitfully applied in the context of transport geography (see Grubesic and Wei, 2012; Martin and Roman, 2001; and Tapiador et al., 2008 for examples of DEA application); yet, they do not consider risk at least explicitly. In this context, the ADI may validly complement DEA and SFA. Second, the ADI may contribute to the undertaking of impact and added value analysis. In the great majority of cases, this is usually based on Cost-Benefit Analysis (CBA) methodologies possibly in conjunction with Input/Output (I/O) or preferably General Computable Equilibrium (CGE) modelling (e.g. see Stabler et al., 2010). Again, these techniques do not prioritise risk and geography. Hence, the ADI may be a welcoming suggestion.

Finally, the ADI may also be of use to airport managers from a financial perspective. For instance, the ADI may be cross tabulated with an airport's EBITDA (Earnings Before Interest, Taxes, Depreciation and Amortisation), which is a measure of gross profit. When a high ADI is combined with a low EBITDA, the airport is undoubtedly in a weak situation and radical measures need to be undertaken. Conversely, an 'allstar' airport would be characterised by a low ADI and a high EBITDA. The real challenge lies in the case where a high ADI is combined with a high EBITDA - such an airport would be a 'fragile beauty' and its managers should actively consider actions to reduce dependency and not sit on the laurels of high profitability. Likewise, an airport with a low ADI and a low EBITDA would have to undertake measures to boost profitability but not at the cost of increased dependency. For the above reasons, it is therefore believed that the proposed ADI may prove a useful contribution not only to the academic literature of transport geography but also to airport strategic management and policymaking. 


\section{References}

ACI-Europe (Airports Council International-Europe). (2010). The Ownership of Europe's Airports. ACI-Europe, Brussels.

Adelman, M. A. (1951). The measurement of industrial concentration. The Review of Economics and Statistics, 33(4), 269-296.

Booysen, F. (2002). An overview and evaluation of composite indices of development. Social Indicators Research, 59(2), 115-151.

Burghouwt, G. (2007). Airline Network Development in Europe and its Implications for Airport Planning. Ashgate, Aldershot.

Bush, H. and Starkie, D. (2014). Competitive drivers towards improved airport/airline relationships. Journal of Air Transport Management, 41(October), 45-49.

Cameron, A.C. and Trivedi, P.K. (2005). Microeconometrics: Methods and Applications. Cambridge University Press, Cambridge.

Chakravarty, S. R. (1992). Efficiency and concentration. Journal of Productivity Analysis, 3(3), 249-55.

Clarke, C. J. and Varma, S. (1999). Strategic risk management: the new competitive edge. Long Range Planning, 32(4), 414-424.

Combes, P-P., Mayer, T. and Thisse, J-F. (2008). Economic Geography: The Integration of Regions and Nations. Princeton University Press, Princeton.

Dennis, N. (2005). Industry consolidation and future airline network structures in Europe. Journal of Air Transport Management, 11(3), 175-183.

Derudder, B. and Witlox, F. (2009). The impact of progressive liberalisation on the spatiality of airline networks: a measurement framework based on the assessment of hierarchical differentiation. Journal of Transport Geography, 17(4), 276-284.

Dobruszkes, F. (2009). Does liberalisation of air transport imply increasing competition? Lessons from the European case. Transport Policy, 16(1), 29-39.

Dobruszkes, F. and Van Hamme, G. (2011). The impact of the current economic crisis on the geography of air traffic volumes: an empirical analysis. Journal of Transport Geography, 19(6), 1387-1398.

du Pisanie, J. (2013). Concentration measures as an element in testing the structureconduct-performance paradigm, ERSA working paper 345, National Treasury of South Africa.

EC (European Commission). (2007). Guide to European Community Legislation in the Field of Civil Aviation, European Commission, Brussels.

EC (European Commission). (2009). Press Release: EU and West African Economic and Monetary Union Sign a Horizontal Agreement on Air Services. European Commission, Brussels. 
EC (European Commission. (2014a). Guidelines on State Aid to Airports and Airlines (2014/C 99/03), Official Journal C99, 4 April, European Commission, Brussels.

EC (European Commission). (2014b). European Civil Aviation Handbook: Part III. International Agreements: Horizontal Agreements and Other Agreements. European Commission, Brussels.

EC (European Commission). (2014c). European Civil Aviation Handbook: Part III. International Agreements: EU-Canada, EU-Morocco, EU-USA. European Commission, Brussels.

EC (European Commission). (2014d). Press Release: EU-ASEAN Aviation Summit Proposes "Open Skies" Agreement. European Commission, Brussels.

Farmaki, A. and Papatheodorou, A. (2015). Stakeholder perceptions of the role of low-cost carriers in insular tourism destinations: the case of Cyprus, tourism planning and development. Tourism and Hospitality Planning \& Development, forthcoming. DOI: $10.1080 / 21568316.2015 .1013566$.

Francis, G., Fidato, A. and Humphreys, I. (2003). Airport-airline interaction: the impact of low-cost carriers on two European airports. Journal of Air Transport Management, 9(4), 267-273.

Francis, G., Humphreys, I. and Ison, S. (2004). Airports' perspectives on the growth of low-cost airlines and the remodeling of the airport-airline relationship. Tourism Management, 25(4), 507-514.

Fuellhart, K. (2003). Inter-metropolitan airport substitution by consumers in an asymmetrical airfare environment: Harrisburg, Philadelphia and Baltimore. Journal of Transport Geography, 11(4), 285-296.

Gaile, G. L. (1984). Measures of Spatial Equality. In Gaile, G. L. and Willmott, C., (Eds). Spatial Statistics and Models. D. Reidel Publishing Co., Hingham, Mass., 223233.

Gillen, D. and Lall, A. (1997). Developing measures of airport productivity and performance: an application of data envelopment analysis. Transportation Research Part E: Logistics and Transportation Review, 33(4), 261-273.

Gillen, D. and Lall, A. (2004). Competitive advantage of low-cost carriers: some implications for Airports. Journal of Air Transport Management, 10(1), 41-50.

Gilroy, B., Lukas, E. and Volpert, T. (2005). The European 'no-frills' aviation market: current and future developments. In Forsyth, P., Gillen, D., Mayer, O. and Neimeier, H.-M., (Eds). Competition versus Predation in Aviation Markets. Ashgate, Aldershot, 203-233.

Graham, A. (2013). Understanding the low cost carrier and airport relationship: a critical analysis of the salient issues. Tourism Management, 36, 66-76.

Graham, A. (2014). Managing Airports: An International Perspective, fourth edition. Routledge, London. 
Graham, B. and Shaw, J. (2008). Low-cost airlines in Europe: reconciling liberalisation and sustainability. Geoforum, 39(3), 1439-1451.

Grubesic, T. H. and Wei, F. (2012). Evaluating the efficiency of the Essential Air Service program in the United States. Transportation Research Part A: Policy and Practice, 46(10), 1562-1573.

Hagigi, M. and Sivakumar, K. (2009). Managing diverse risks: an integrative framework. Journal of International Management, 15(3), 286-295.

Halpern, N. (2008). Lapland's airports: facilitating the development of international tourism in a peripheral region. Scandinavian Journal of Hospitality and Tourism, 8(1), $25-47$.

Halpern, N. (2011). Measuring seasonal demand for Spanish airports: implications for counter-seasonal marketing. Research in Transportation Business and Management, $1(1), 47-54$.

Halpern, N. and Graham, A. (2013). Airport Marketing. Routledge, Abingdon.

Hannah, L. and Kay, J. A. (1977). Concentration in Modern Industry: Theory, Measurement and the UK Experience, Macmillan, London.

Krugman, P. R. (ed.) (1986). Strategic Trade Policy and the New International Economics. Massachusetts Institute of Technology, Cambridge, MA.

Linkweiler, H. (2013). What airports can do in the event of the failure of their main airline. Journal of Airport Management, 7(2), 129-135.

Lipczynski, J., Wilson, J. and Goddard, J. (2009). Industrial Organization: Competition, Strategy, Policy, 3rd edition. Prentice Hall, Harlow.

Mack, E., Grubesic, T. H. and Kessler, E. (2007). Indices of industrial diversity and regional economic composition. Growth and Change, 38(3), 474-509.

Martin, J. C. and Roman, C. (2001). An application of DEA to measure the efficiency of Spanish airports prior to privatization. Journal of Air Transport Management, 7(3), 149-157.

Mason, K., Morrison, W. and Stockman, I. (2013). Liberalisation of air transport in Europe and the evolution of 'low-cost' airlines. In Forsyth, P., Gillen, D., Huschelrath, K., Neimeier, H.-M. and Wolf, H., (Eds). Liberalisation in Aviation. Ashgate, Farnham, 141-156.

Mazzocchi, M., Hansstein, F. and Ragona, M. (2010). The 2010 volcanic ash cloud and its financial impact on the European airline industry. CESifo Forum, 2, 92-100.

Moreira, S. B., Simões, N. and Crespo, N. (2012). Composite Indicators of Development: The Importance of Weights. In: Conference on New Challenges of Economic and Business Development. University of Latvia, Riga, May 10-12.

O'Connor, K. (2003). Global air travel: toward concentration or dispersal? Journal of Transport Geography, 11(2), 83-92. 
Palan, N. (2010). Measurement of Specialization: The Choice of Indices, FIW Working Paper $\mathrm{N}^{\circ} 62$.

Papatheodorou, A. and Arvanitis, P. (2009). Spatial evolution of airport traffic and air transport liberalisation: the case of Greece. Journal of Transport Geography, 17(5), 402-412.

Parton, J. and Ryley, T. (2012). A business analysis of XL Airways: what lessons can be learned from the failure? Journal of Air Transport Management, 19, 42-48.

Reynolds-Feighan, A. (1998). The impact of US airline deregulation on airport traffic patterns. Geographical Analysis, 30(3), 234-253.

Reynolds-Feighan, A. (2001). Traffic distribution in low-cost and full-service carrier networks in the US air transportation market. Journal of Air Transport Management, $7(5), 265-275$.

Reynolds-Feighan, A. (2007). Competing networks, spatial and industrial concentration in the US airline industry. Spatial Economic Analysis, 2(3), 237-257.

Saisana, M. and Tarantola, S. (2002). State-of-the-art Report on Current Methodologies and Practices for Composite Indicator Development. Joint Research Centre, European Commission, Brussels.

Scotti, D., Malighetti, P., Martini, G. and Volta, N. (2012). The impact of airport competition on technical efficiency: a stochastic frontier analysis applied to Italian airports. Journal of Air Transport Management, 22, 9-15.

Sen, A. (1976). Poverty: an ordinal approach to measurement. Econometrics, 44(2), 219-31.

Stabler, M., Papatheodorou, A. and Sinclair, M. T. (2010). The Economics of Tourism, second edition. Routledge, London.

Starkie, D. (2012). European airports and airlines: evolving relationships and the regulatory implications. Journal of Air Transport Management, 21, 40-49.

Suau-Sanchez, P. and Burghouwt, G. (2011). The geography of the Spanish airport system: spatial concentration and deconcentration patterns in seat capacity distribution, 2001-2008. Journal of Transport Geography, 19(2), 244-254.

Taleb, N. N. (2007). The Black Swan: The Impact of the Highly Improbable. Penguin, London.

Tapiador, F. J., Mateos, A. and Martí-Henneberg, J. (2008). The geographical efficiency of Spain's regional airports: A quantitative analysis. Journal of Air Transport Management, 14(4), 205-212. 